\title{
Differences in canopy cover estimations from ALS data and their effect on fire predictions
}

Ritu Taneja ( $\square$ s3704716@student.rmit.edu.au )

RMIT University https://orcid.org/0000-0001-7477-7419

\section{Luke Wallace}

University of Tasmania

Karin Reinke

RMIT University

James Hilton

CSIRO: Commonwealth Scientific and Industrial Research Organisation

Simon Jones

RMIT University

\section{Research Article}

Keywords: canopy cover, fire spread models, Airborne Laser Scanning, Fuel assessment, fire predictions

Posted Date: February 23rd, 2022

DOI: https://doi.org/10.21203/rs.3.rs-1242380/v1

License: (c) (i) This work is licensed under a Creative Commons Attribution 4.0 International License.

Read Full License 


\title{
Differences in canopy cover estimations from ALS data and their effect on fire prediction
}

\author{
Ritu Taneja ${ }^{1 *}$, Luke Wallace ${ }^{2}$, Karin Reinke ${ }^{1}$, James Hilton ${ }^{3}$ \\ and Simon Jones ${ }^{1}$ \\ ${ }^{1 *}$ School of Science, RMIT University, 124 La Trobe St, \\ Melbourne, 3000, VIC, Australia. \\ ${ }^{2}$ School of Geography, Planning, and Spatial Sciences, University \\ of Tasmania, Churchill Ave, Hobart, 7005, TAS, Australia. \\ ${ }^{3}$ Data61, CSIRO, Research Way, Clayton, Melbourne, 3168, VIC, \\ Australia.
}

${ }^{*}$ Corresponding author(s). E-mail(s): s3704716@student.rmit.edu.au;

Contributing authors: luke.wallace@utas.edu.au; karin.reinke@rmit.edu.au; james.hilton@csiro.au; simon.jones@rmit.edu.au;

\begin{abstract}
Canopy cover is a primary attribute used in empirical wildfire models for certain fuel types. Accurate estimation of canopy cover is key to ensuring accurate prediction of fire spread and behaviour in these fuels. Airborne Laser Scanning (ALS) is a promising active remote sensing technology for estimating canopy cover in natural eco-systems since it can penetrate and measure the vegetation canopy. Various methods have been developed to estimate canopy cover from ALS data. However, little attention has been given to the evaluation of algorithms used to calculate canopy cover and the subsequent influence these algorithms can have on wildfire behaviour models. In this study we evaluate the effect of using different algorithms to calculate canopy cover on the performance of the Australian Mallee-heath fire spread model. ALS data was used to derive five canopy cover models. Fire spread metrics including burned area, unburned area within the fire extent, and extent of fire were compared for different model run times. The results show that these metrics are strongly influenced by choice of algorithm used to calculate canopy
\end{abstract}


cover. The results from this study may provide practical guidance for the optimal selection of estimation methods in canopy cover mapping.

Keywords: canopy cover, fire spread models, Airborne Laser Scanning, Fuel assessment, fire predictions

\section{Introduction}

Shrubland ecosystems are globally distributed and highly heterogeneous in structure and plant species composition. Under certain conditions, fires in shrubland ecosystems can spread fast with high intensity $[1,2]$. These fires have the potential to burn extensive areas under extreme fire conditions, threatening human life, property and a result in broad range of environmental impacts [3]. Recent advances in computational models have shown the potential to predict fire behavior effectively $[2,4,5]$. These models are used to characterize fire behavior under specific fuel and weather conditions and predict fire spread during a fire event [2].

In semi-arid environments, fuels are often organised in stratified layers and discrete clumps separated by bare ground $[2,6]$. Discontinuities in the horizontal distribution of canopy fuels associated with large-scale heterogeneous fuel complexes cause discontinuous fire behaviour. For example Oak chaparral in California [7], sage brush in the interior Western US and Mallee-heath [8] and hummock grasslands [2,9] in Australia. A small change in the drivers of the fire can lead to a large change in resulting fire behaviour, including transitions from surface to a crown fire, with a corresponding increase in the rate of spread [1].

Given the influence of fuel characteristics on the behaviour of fire, it is essential to explicitly account for the effects of vegetation structure when exploring the interaction between forest structure and fire behaviour [5, 1015]. Parsons et al. [14] suggests that fine-scale canopy fuel spatial patterns can affect both mean and variability in fire behavior outcomes and canopy cover is one of the strongest drivers of changes in fire metrics.

It is a time-consuming challenge for managers to collect accurate field information throughout the lifecycle of wildfires. However, recent developments in remote sensing technology provides researchers with an opportunity to quantify and map patterns of variation in forest cover and health assessment across space and time [16, 17]. Satellites and aircraft are the main platforms used to collect such data. Satellites are suitable for covering a large area, and for conducting multi-temporal analysis. However, due to limited penetration capability of optical imagery in vegetated areas, satellite imagery is currently unable to provide detailed measurements of forest structure often required for use in fire simulation models [18], although space based laser ranging technologies, for example NASA's Global Ecosystem Dynamics Investigation, 'GEDI' are progressively bridging this gap [19, 20]. 
Airborne Laser Scanning (ALS) is an active remote sensing technique which utilises reflections from laser pulses emitted at known locations to determine the 3D properties of the environment [21]. Ongoing research into the processing and analysis of ALS data has allowed for the development of an extensive range of ALS data products from which a wide range of forest metrics can be derived [22-24]. Studies have shown that ALS can provide reliable estimates of $3 \mathrm{D}$ forest canopy structure [21, 25-27]. Due to its ability to penetrate through forest canopy, ALS provides superior canopy cover estimates to airborne and satellite imagery [28, 29].

Various algorithms have been developed to estimate canopy cover from ALS data based on both the geometry of the captured scene and the properties of the returns within that scene [21,30-32]. Furthermore, previous studies have indicated that ALS based estimations of canopy cover can be affected by many factors, such as LiDAR scan angle [33], ALS point density [21], and forest composition [34]. However, we currently lack a thorough understanding of how the properties of these algorithms, data capture and forest structure across a range of different forest types influence canopy cover estimations. Any differences in canopy cover, due to the choice of algorithm, are likely to result in unknown variations of predicted fire behaviour from the empirical models which use this metric. Given the potential of ALS data and the ability to derive fuel maps at high spatial resolutions, a greater understanding of how different algorithms to derive canopy cover interact with existing fuel models is required.

For improving predictions of fire behaviour, it is critical to understand the sensitivity of fire behaviour models to the variation in canopy cover descriptions. The increasing availability and diversity of new methods for deriving canopy cover for consumption into fire behaviour models requires an understanding of how different methods for estimating the same metric can affect model outputs as a first step towards improving predictions.

In this study, we investigate the effect of ALS-derived canopy cover estimates from different ALS processing algorithms on the outcomes (burned area, unburned area ratio and fire extent) of a Mallee-heath fire spread model. To date, a generalised understanding of how algorithms to derive fuel related input data affect fire behaviour in this environment is lacking. This study therefore fills an essential knowledge gap by providing information on (1) how five different canopy cover estimate algorithms in mallee-heath vegetation types produce cover estimates and (2) the impact of these different canopy cover estimates on fire behaviour model outputs such as burned area, unburned area ratio and fire extent.

\section{Materials and methods}

\subsection{Study Area}

The study site for this experiment is located $25 \mathrm{~km}$ north of Renmark in South Australia on Calperum station ( $\left.33^{\circ} 44^{\prime} 49^{\prime \prime} \mathrm{S}, 140^{\circ} 52^{\prime} 22^{\prime \prime} \mathrm{E}\right)$ Figure 1. It is one 
of the super-sites of the Australian Terrestrial Ecosystem Research Network (TERN). TERN is Australia's land ecosystem observatory, where key terrestrial ecosystem attributes over time are measured from continental scale to field sites at hundreds of representative locations [35]. This site was chosen due to the availability of a published empirical fire spread model for the fuel type at the site (Section 2.6) and high-resolution remote sensing data (Section 2.2). The Calperum area is important because of presence of several threatend bird species, wetlands adjacent to the Murray river and intact Mallee vegetation [36].
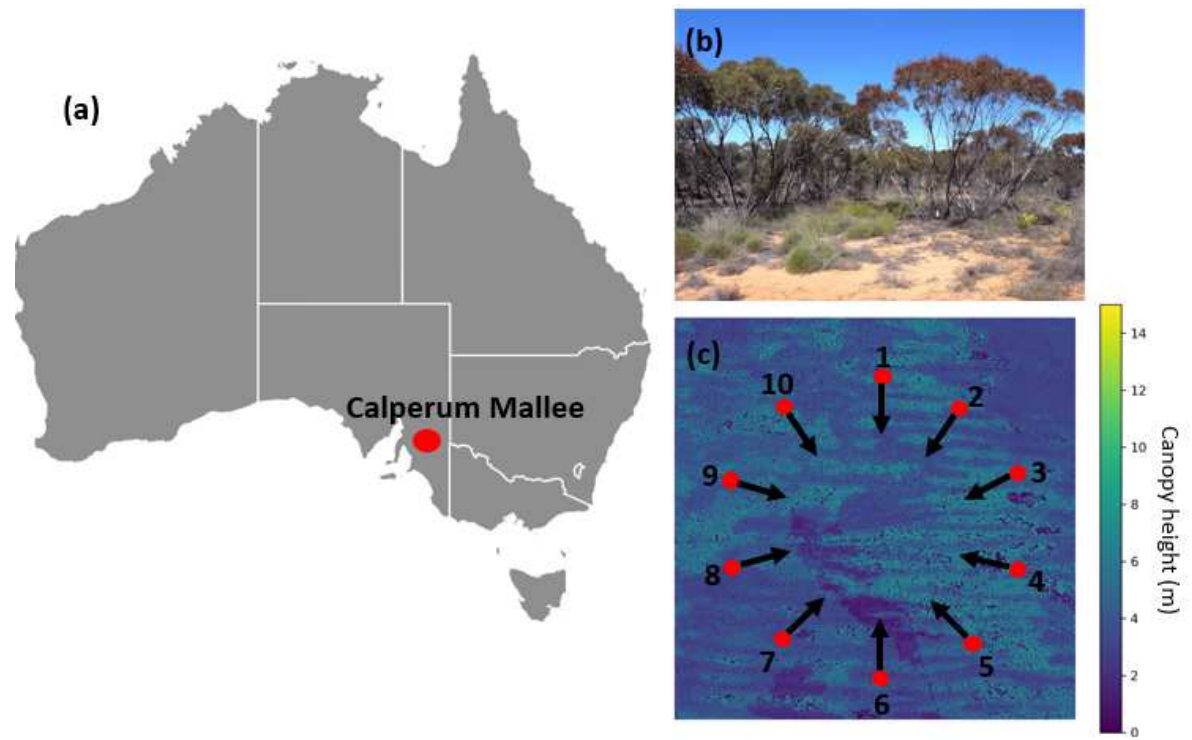

Fig. 1: Study area. (a) Location of the study area in southeast of the state of South Australia. (b) Vegetation present in the study area (Source: https://supersites.tern.org.au/supersites/clpm) (c) Plot design used for the study area showing the location of 10 ignition points in red superimposed on a canopy height map. The wind direction at each ignition point is shown as black arrows. The points were chosen to be $1.5 \mathrm{~km}$ from the centre of the area and at $36^{\circ}$ intervals from each other.

The vegetation in the area is dominated by eucalypt trees of four species (Eucalyptus dumosa, Eucalyptus incrassata, Eucalyptus oleosa and Eucalyptus socialis). Their distribution is influenced by a number of factors, including rainfall, soil type and fire history, at different spatial and temporal scales. These multi-stem trees are typically sparsely distributed across the landscape and grow between 3.5 and $7 \mathrm{~m}$ [36]. Eremophila, Hakea, Olearia, Senna and Melaleuca genera are sparsely distributed in the mid-story. Across the site hummock and tussock grasses are also present as an understorey. 
The climate is semi-arid characterised by extremely hot, dry summers and cool winters. The mean annual rainfall ranges between 200 and $340 \mathrm{~mm}$ (annual extremes are 72-694 $\mathrm{mm}$ ). Daily maximum temperatures can reach up to $40^{\circ} \mathrm{C}$ in the summer and winters are generally dry and mild with an average maximum of $16^{\circ} \mathrm{C}$. The landscape is an extensive plain with the River Murray, its anabranches and floodplain wetlands forming the major topographic feature [36].

The central and south-east areas of the site are characterised by sand dune and swale systems that run approximately east-west, with undulation from swale to crest up to $8 \mathrm{~m}$ in elevation [36]. Dunes support a canopy of Malleeheath with a Triodia understorey [37]. These areas present the greatest fire risk in Mallee-heath systems due to the extreme flammability of Triodia. This risk increases with seasonal conditions such as above-normal rainfall [2]. A strong response of ephemeral herbs and grasses to wet years create continuous fuel conditions which can lead to extensive fires in this vegetation $[6,38]$. Essentially, fire behaviour in Mallee-heath is a function of complex interactions between vegetation types and the seasonal conditions.

\subsection{ALS data and pre-processing}

The ALS data used in this study was obtained from TERN AusCover [35]. A Riegl LMS-Q560 full-waveform laser scanner was flown at a height $300 \mathrm{~m}$ above ground level to capture small footprint data over $5 \times 5 \mathrm{~km}$ study site. Data was captured using regular north-south oriented flight-lines with a spacing of approximately $125 \mathrm{~m}$. The swath overlap between flight lines was $50 \%$. The scanner has a beam divergence of $0.5 \mathrm{mrad}$ resulting in a laser footprint of $30 \mathrm{~cm}$ on the ground. The scan angle was limited to $-22.5^{\circ}$ to $+22.5^{\circ}$ in the across-track direction resulting ( $45^{\circ}$ field-of-view).

The full waveform data was processed by the data supplier to produce a discrete return point cloud. This was achieved using Riegel RiAnalyze (version 4.1.2) to identify discrete peaks in the back-scattered signal using a Gaussian Pulse Estimation technique [39], resulting in a maximum of 7 returns per output pulse.

Discrete returns were classified into either ground or non-ground using the Cloth Simulation Filter (CSF). A complete description of the CSF algorithm and the various parameters can be found in [40]. In brief, this filter identifies points that are most likely belonging to the ground through the simulation of a rigid cloth draped over the point set. The filter is parameterised using class threshold, resolution, time step and rigidness parameters. In this case values of $0.02,5,2$ and 3 were applied for class threshold, resolution, time step and rigidness respectively. Once the ground points were identified, linear interpolation was used to generate a $1 \mathrm{~m}$ resolution Digital Elevation Model (DEM). Subsequently, the Above Ground Height (AGH) of all non-ground points was calculated by subtracting the value of the DEM elevation at each horizontal location. 


\subsection{Canopy metrics derivation}

The fire model described in Section 2.6 requires both canopy height and canopy cover as input. Both canopy cover and height metrics were derived at $10 \mathrm{~m}$ resolution grid. A scale of $10 \mathrm{~m}$ was used as Taneja et al. [41] showed that both canopy height and cover are spatially correlated up this distance in Mallee vegetation. Canopy height was calculated as the 95th percentile of the AGH of the non-ground points falling within each cell. Mahoney at al. [42] suggests that 95th percentile is the logical height percentile for validating Australia-wide predictions of canopy height. Furthermore, the typical accuracies associated with ALS height information with respect to ground estimates, 95th percentile is assumed to be an adequate estimate of true canopy height across Australia [43]. Canopy cover was calculated using the approaches described in the following section.

\subsection{Canopy cover calculation}

Five different methods were used to calculate canopy cover from the ALS data. These were:

1. First Cover Index (FCI)

2. Last Cover Index (LCI)

3. Solberg Cover Index (SCI)

4. Alpha Cover Index (ACI)

5. Grid Cover Index (GCI)

The details of these methods are described in the following section. These can be broadly grouped into two categories: (1) return-based metrics (FCI, SCI and LCI), where canopy cover is based on the height and type of return (i.e. first, only or last return from an outgoing pulse) and (2) geometric-based metrics (ACI and GCI) where canopy cover is based on the geometry of the returns above a certain height. In all cases we consider canopy returns to be any returns that occur greater than $1.35 \mathrm{~m}$ above the ground (Figure 2), as this height has been shown to efficiently separate the tree crowns from the understorey and ground vegetation [44]. 


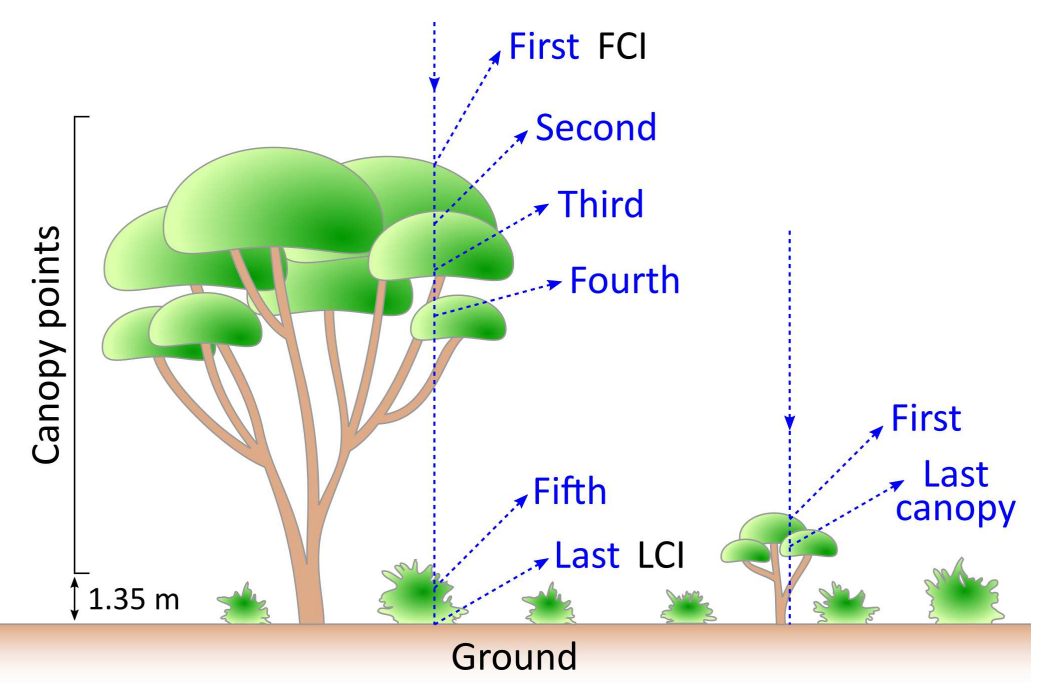

Fig. 2: Diagram showing number of returns belonging to corresponding returnbased cover estimates.

\subsubsection{Return-based metrics of canopy cover}

Three return-based indices utilise the properties of laser pulses to determine a measure of canopy cover. These laser pulses are emitted from the ALS system and reflect from objects both on and above the ground surface including trees, other vegetation (grasses and shrubs), buildings and the ground. Pulses passing through the environment may be partially or fully intercepted by any objects it encounters. When only one return is triggered per pulse this is termed as single return, whereas multiple returns occur when several objects reflect enough light back to the sensor from a single pulse. The returns from a multiple-return pulse can be categorised as first returns, intermediate returns and last returns as shown in Figure 2. For example a pulse may reflect from upper canopy first (first return), then the lower tree canopy, stems, understorey vegetation (intermediate returns) as finally the ground (last return), resulting in multiple measurable returns from that pulse.

The first return laser pulse is the most significant return and will be associated with the highest feature in the landscape like a treetop as shown in Figure 2. The first return can also represent the ground in an area which has no vegetation or any other feature. In this case only single return will be detected by the ALS system. It is important to note that the last return will not always be from a ground return. For example, when a pulse hits a thick branch on its way to the ground and the pulse does not actually reach the ground, the last return is not from the ground but from the branch that reflected the entire laser pulse. The intermediate returns, in general, provide an indication of vegetation structure. 
The first method, the First Cover Index (FCI) described in Morsdorf et al. [45], uses the proportion of first (First canopy $_{\text {) }}$ ) and single $\left(\right.$ Single $\left._{\text {canopy }}\right)$ returns from the canopy to the total number of first $\left(\right.$ First $\left._{\text {all }}\right)$ and single $\left(\right.$ Single $\left._{\text {all }}\right)$ returns within an area, to provide an estimate of canopy cover as follows;

$$
F C I=\frac{\sum \text { Single }_{\text {canopy }}+\sum \text { First }_{\text {canopy }}}{\sum \text { Single }_{\text {all }}+\sum \text { First }_{\text {all }}}
$$

The second method, the Last Cover Index (LCI) given in Korhonen et al. [21] is based on the proportion of last return (Last Canopy $_{\text {) }}$ and single

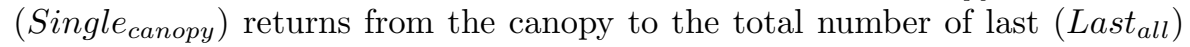
and single $\left(\right.$ Single $\left._{\text {all }}\right)$ returns within an area, to provide an estimate of canopy cover as follows;

$$
L C I=\frac{\sum \text { Single }_{\text {canopy }}+\sum \text { Last }_{\text {canopy }}}{\sum \text { Single }_{\text {all }}+\sum \text { Last }_{\text {all }}}
$$

The third method, the Solberg's Cover Index (SCI) given in Solberg et al. [46], which takes into account both single first and last returns from the canopy and the ground as follows;

$$
S C I=1-\frac{\sum \text { Single }_{\text {ground }}+0.5\left(\sum \text { First }_{\text {ground }}+\sum \text { Last }_{\text {ground }}\right)}{\sum \text { Single }_{\text {all }}+0.5\left(\sum \text { First }_{\text {all }}+\sum \text { Last }_{\text {all }}\right)}
$$

The coefficient 0.5 is a weight for pulses that produce both first and last echoes, and it can be adjusted if necessary [46]. For instance, a pulse that produces both canopy-first and ground-last echoes is assigned penetration of 0.5 . For a single ground echo the penetration is 1 , and for a single canopy echo it is 0 .

\subsubsection{Geometric-based metrics of canopy cover}

The grid cover index (GCI) introduced by Korhonen et al. [21] uses the vertical projection of cover points defined across a 2D binary grid. Following Korhonen et al. [21] a binary $0.1 \mathrm{~m}$ resolution grid was created within cells containing a canopy return given a value of 1 , while others were labeled with 0 . Morphological closing is then applied to the canopy map to remove small gaps in the data. This is followed by morphological opening which allows any unnecessary detail and outliers to be removed. Cover is then calculated as the percentage of $1 \mathrm{~m}$ cells within each $10 \mathrm{~m}$ grid cell area containing labeled with a 1 .

The alpha cover index (ACI) applied to ALS data [31] uses alpha shapes to map the crown area based on the $2 \mathrm{D}$ projection of crown strikes. The parameter $\alpha$ is used to tune the "tightness" of the shape around the points. For a very large value of $\alpha$, the shape is equivalent to the convex hull. For a very small value of $\alpha$, the $\alpha$-shape forms holes and pockets with the shape clustering around the original points. Cover is then calculated as the percentage of area of the $10 \mathrm{~m}$ grid cell covered by an alpha shape. To accurately capture the 
variations within the crown and eliminate any unnecessary noise, $\alpha$ was chosen as a function of the point density. As per the recommendation from [31], value of $\alpha$ was chosen to be $1 \mathrm{~m}$ and $0.5 \mathrm{~m}$ for this study. ACI1 represents alpha cover index with $\alpha$ as $1 \mathrm{~m}$ and ACI05 represents alpha cover index with $\alpha$ as $0.5 \mathrm{~m}$.

\subsection{Ground estimates of canopy cover}

The ground estimates of canopy cover were downloaded from the TERN data portal [47] and compared with cover estimates derived from ALS data. These estimates were collected following the TERN supersite monitoring protocols [47].

The ground estimates of canopy cover were obtained using Digital Canopy Photography method (DCP) $[48,49]$ for a 100 by $100 \mathrm{~m}$ area immediately to the North West of the flux tower present in the study area. Photographs were taken at the intercepts along ten $100 \mathrm{~m}$ east west transects with transects at 10 $m$ North South intervals [47]. This approach was used to characterize canopy cover for a 1 ha area. At each point a single upward looking digital image was captured. The image was then classified into canopy and sky pixels. Sky pixels were further classified as those occurring between crown elements and those occurring outside of the crown area. Canopy cover $(f c)$ is defined as the fraction of canopy pixels including sky pixels that lie in between small crown gaps [48].

Ground observation data did not contain accurate location coordinates therefore preventing direct comparison with ALS data. In lieu of direct comparison, a comparison between the properties of the population of canopy cover estimates from the field with ALS based estimates within the $140 \times 140 \mathrm{~m}$ area directly North West of the flux tower. A two sample t-test was then made between each set of ALS metrics and the ground estimates to determine if mean of ground estimates is same or significantly different from mean of each ALS metrics.

\subsection{Fire spread model}

Fire behaviour in semi-arid Mallee-heath is modelled by an empirical Malleeheath fire spread model developed by Cruz et al. [2]. This model predicts the likelihood of fire propagation, type of fire (surface or crown fire), and forward rate of spread. The probability of successful fire spread, $P_{s}$, is given by:

$$
P_{s}=\frac{1}{1+\exp \left[-\left(14.62+0.207 U_{10}-1.872 M C-0.304 \operatorname{Cov}_{o}\right)\right]}
$$

where $U_{10}$ is $10-\mathrm{m}$ wind speed $(\mathrm{km} / \mathrm{h}), C_{o v}$ is the canopy cover percentage and $M C$ is the moisture content (\%) of the dead litter fuels given by [2]:

$$
M C=4.79+0.173 * R H-0.1 *(T-25)-\Delta * 0.027 * R H
$$

where $R H$ is the relative humidity $(\%), T$ is the air temperature $\left({ }^{\circ} \mathrm{C}\right)$ and $\Delta$ is solar radiation variable. Note Equation (5) only holds during daytime hours $(\Delta=1)$ and 0 otherwise. 
If $P_{s}<0.5$, then fire will be self-extinguishing. If $P_{s} \geq 0.5$, then fire will result in sustained fire spread and for spreading fires, the probability of crown fire propagation is given by $P_{c}$,

$$
P_{c}=\frac{1}{1+\exp \left[-\left(11.138+1.4054 U_{10}-3.4217 M C\right)\right]}
$$

Rather than assuming the fire is a surface or crown, the model uses a probability of crowning, $P_{c}$, to determine overall rate of spread, $R,(\mathrm{~m} \min -1)$ is given by,

$$
R=\left(1-P_{c}\right) \dot{R}_{s}+P_{c} \dot{R}_{c}
$$

where $\dot{R}_{s}$ and $\dot{R}_{c}$ are rate of spread of surface fire and crown fire respectively. $\dot{R}_{s}(\mathrm{~m} / \mathrm{min})$ is given by

$$
\dot{R}_{s}=3.337 * U_{10} * \exp (-0.1284 * M C) * H^{-0.7073}
$$

where $H$ is canopy height $(\mathrm{m})$ and $R_{c}(\mathrm{~m} / \mathrm{min})$ is given by

$$
\dot{R}_{c}=9.5751 * U_{10} * \exp (-0.1795 * M C) *\left(\operatorname{Cov}_{o} / 100\right)^{0.3589}
$$

Noting that from Equation (8) the rate of spread of surface fire is independent of canopy cover.

\subsection{Fire spread modelling environment and parameterisation}

The 'Spark' wildfire simulation framework was used for modelling hypothetical wildfires over our study area using the Mallee-heath rate-of-spread model [50]. Multiple rate-of-spread models can be implemented in Spark using user-defined scripts based on the different fuel types and conditions required for each model [51]. The framework supports standard geospatial data types for fuel layers and meteorological conditions. The system requires the ignition conditions of the fire in the form of points, lines or polygons. Typically, topography information is also required as the speed of a fire is dependent on the slope of the terrain. However, topography was held constant for the simulations as the focus of this study is to determine the impact of canopy cover calculations on the fire spread model.

The area for which the fire could be modelled was limited by the extent of the airborne ALS capture $(5 \times 5 \mathrm{~km})$. As such, and in order to remove any spatial bias in the fuel distribution pattern (e.g., horizontal striations), 10 ignition points were distributed evenly (at $36^{\circ}$ intervals) around the edges of a $1.5 \mathrm{~km}$ radius circle centred within the data capture as shown in Figure 1. At each ignition point, the wind direction was set such that the fire would pass through the centre of the study area. This allowed for a model duration of one hour and ensured each simulated fire extent remained within the footprint of the ALS data. Furthermore, this also served to remove any directional bias in 
the results as the fires originated from different start points spread equidistant around the study area for each of the 10 simulations.

To determine the effect of cover calculations on fire spread model, other parameters such as weather and topography affecting fire propagation, were held constant for each simulation. Empirical models developed from experimental data with sound functional forms have been shown to work well for wildfire situations where the environmental drivers are well over the range of the experimental datasets [52]. In this study we simulate fire under following fire weather conditions: wind speed was set to $30 \mathrm{~km} \mathrm{hr}^{-1}$, temperature was fixed at $25^{\circ} \mathrm{C}$ and relative humidity was set to $10 \%$. Under these conditions fire can transition from surface to crown in this fuel type [2].

The Spark simulations were run for each canopy cover grid as derived from each of the different canopy cover calculation methods, at each ignition point. The raster resolution of the model simulations was set to $1 \mathrm{~m} \times 1 \mathrm{~m}$, with all input and output raster layers resampled to this resolution. Once the simulated fire reached the cell's centroid, the cell was considered ignited (and burned by the end of the simulation) and the current time was recorded as the arrival time of fire at that particular location. After the simulation was complete, isochrones denoting fire spread over time were generated.

\subsection{Fire behaviour metrics}

For this study, all simulations were summarised by the total area burned by fire and the unburned area ratio. Area burned is a commonly used metric when fire behavior and effects are being examined. It has been used in addressing many ecological and Earth science challenges, including characterizing wildfires and evaluating their impacts [53-55]. However, area alone often ignores the existence of unburned area within a fire perimeter (depending on the level of detail in the observational data); discriminating between burned/unburned area is an important component of the burn mosaic [56-58]. The unburned area ratio is defined as the ratio between the unburned area within the fire perimeter and the total area of the fire perimeter. The fire perimeter was defined by an alpha shape $($ alpha $=1.5)$ created around the centre point of all burned cells and includes unburned areas inside this polygon. The area burned was estimated as the summed area of the grid cells burned at the end of the simulation.

For operationally predictive fire behaviour model, it is assumed that fuels are uniform and continuous for the period of application of the model [59]. A simulation was conducted for a homogeneous fuel distribution, in which canopy cover percentage and height were assumed to be constant. The canopy cover varies between coastal shrublands to sparse heathlands (10-30\%) in semi-arid environments Cruz et al. [59]. Furthermore, while evaluating the impact of wind speed and moisture content on the likelihood of fire prediction in semiarid Mallee-heath model, Cruz et al. [59] assumed a canopy cover of $33 \%$. With this in mind, canopy cover for homogeneous fuel distribution case was fixed at $30 \%$. Canopy height was calculated by taking the average of canopy 
heights calculated as the 95 th percentile of the AGH of the non-ground points falling within 10-m cell. These values have been selected to be representative of the fuel conditions only. The outcomes of this simulation (referred to as 'hom' throughout this study) serves as a point of inter-comparison between the outcomes of simulations using the different cover methods.

The Jaccard Similarity Index $(J)$ was used to compare the area burned for each simulation with area burned for homogeneous landscape simulation. Several studies have used $J$ to compare actual fire events with simulated fires [60]. This index simply express the proportion of burned cells common between two fire simulations and is given by

$$
\text { Jaccard Similarity Index }(J)=\frac{(A \cap B)}{(A \cup B)}
$$

where $A=$ number of grid cells burned in simulations running with different cover methods and $B=$ number of grid cells burned in homogeneous landscape.

\section{Results}

\subsection{Canopy cover estimates}

Figure $3 \mathrm{~b}$ shows the distribution of canopy cover estimates obtained from different algorithms using ALS data and DCP for 1 ha area. Within the 1 ha area, the mean of the ground estimates of canopy cover, $f c$, was $54 \% \pm$ $24 \%$. The null hypothesis of the two sample t-test at the $5 \%$ significance level was rejected for all ALS based cover calculation approaches except for ACI1 $(\mathrm{h}=0$, mean of $51 \% \pm 16 \%)$. This shows that canopy cover estimates using ACI1 approach are similar to ground estimates. The grid based approach overestimated the mean canopy cover in 1 ha area, whilst ACI05 and the return-based approaches underestimated canopy cover (Figure 3b).

Figure $3 \mathrm{a}$ shows the distribution of canopy cover estimates obtained from different methods for $5 \mathrm{~km} \times 5 \mathrm{~km}$ study area. Geometric-based canopy cover estimates were found to be greater than the return-based canopy cover estimates. The GCI metric shows the highest mean cover estimate of $60.26 \%$ and the LCI metric shows the smallest mean cover estimate of $2.77 \%$ ( Figure 3 ). Geometric-based methods show greater variation in cover estimates in comparison to the return-based methods (reported in Table 1). The GCI is the only metric which reported maximum canopy cover percent (100\%) i.e. cells covered completely with vegetation. The canopy cover estimates from the LCI metric were found to be least correlated with other cover metrics. The correlation between different cover metrics with each other is reported in Table 1. 

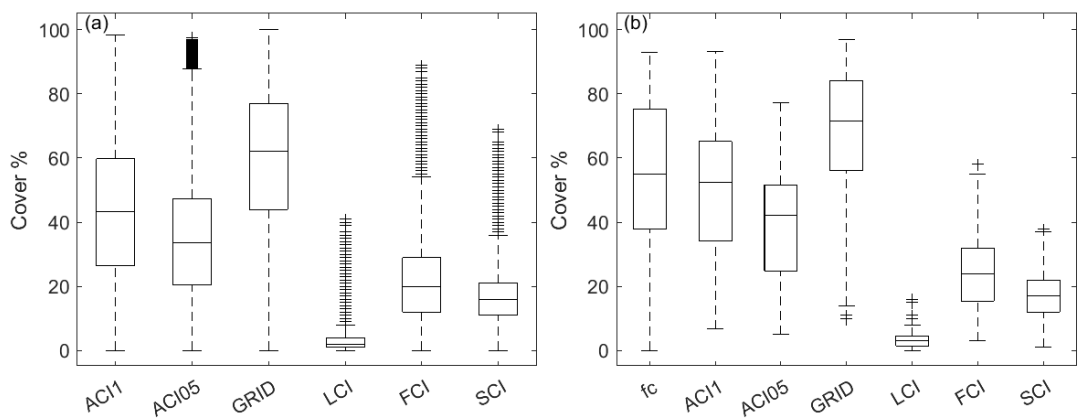

Fig. 3: Boxplot showing canopy cover estimates obtained from different cover methods for (a) $5 \mathrm{~km} \times 5 \mathrm{~km}$ study area and (b) $1 \mathrm{Ha}$ area. Canopy cover estimates from ground estimates are shown as $f c$.

Table 1: Summary statistics from the 10 simulations of canopy cover percentage and coefficient of correlation for the different methods to derive canopy cover from ALS data for $5 \mathrm{~km} \times 5 \mathrm{~km}$ study area.

\begin{tabular}{|c|c|c|c|c|c|c|c|c|c|}
\hline Canopy cover & \multicolumn{3}{|c|}{ Cover (\%) } & \multicolumn{4}{|c|}{ Pearson correlation coefficient } & t-test \\
\hline methods & $\mu$ & $\sigma$ & GRID & ACI1 & ACI05 & FCI & LCI & SCI & p-value \\
\hline GRID & 60.26 & 21.66 & 1 & 0.93 & 0.88 & 0.85 & 0.46 & 0.78 & $<0.01$ \\
ACI1 & 43.85 & 21.85 & 0.93 & 1 & 0.97 & 0.94 & 0.53 & 0.83 & $<0.29$ \\
ACI05 & 34.93 & 18.48 & 0.88 & 0.97 & 1 & 0.97 & 0.59 & 0.85 & $<0.01$ \\
FCI & 21.5 & 12.64 & 0.85 & 0.94 & 0.97 & 1 & 0.69 & 0.89 & $<0.01$ \\
LCI & 2.77 & 2.89 & 0.46 & 0.53 & 0.59 & 0.69 & 1 & 0.73 & $<0.01$ \\
SCI & 16.34 & 7.58 & 0.78 & 0.83 & 0.85 & 0.89 & 0.73 & 1 & $<0.01$ \\
\hline
\end{tabular}

Despite the differences in magnitude of estimated cover the spatial distribution of canopy cover calculated using different methods is similar, as shown in Figure 4. Fire barriers such as roads are distinguishable in geometricbased methods ( Figure 4a, 4b and 4c) as compared to return-based methods ( Figure 4h, 4i and 4j).

In general, the trends shown by different cover estimates for 1 ha area and $5 \mathrm{~km} \times 5 \mathrm{~km}$ study area are same (Figure $3 \mathrm{a}$ and b). Thus, we can hypothesise that these results can be representative of vegetation present in this ecosystem. 
Differences in canopy cover and their effect on fire prediction
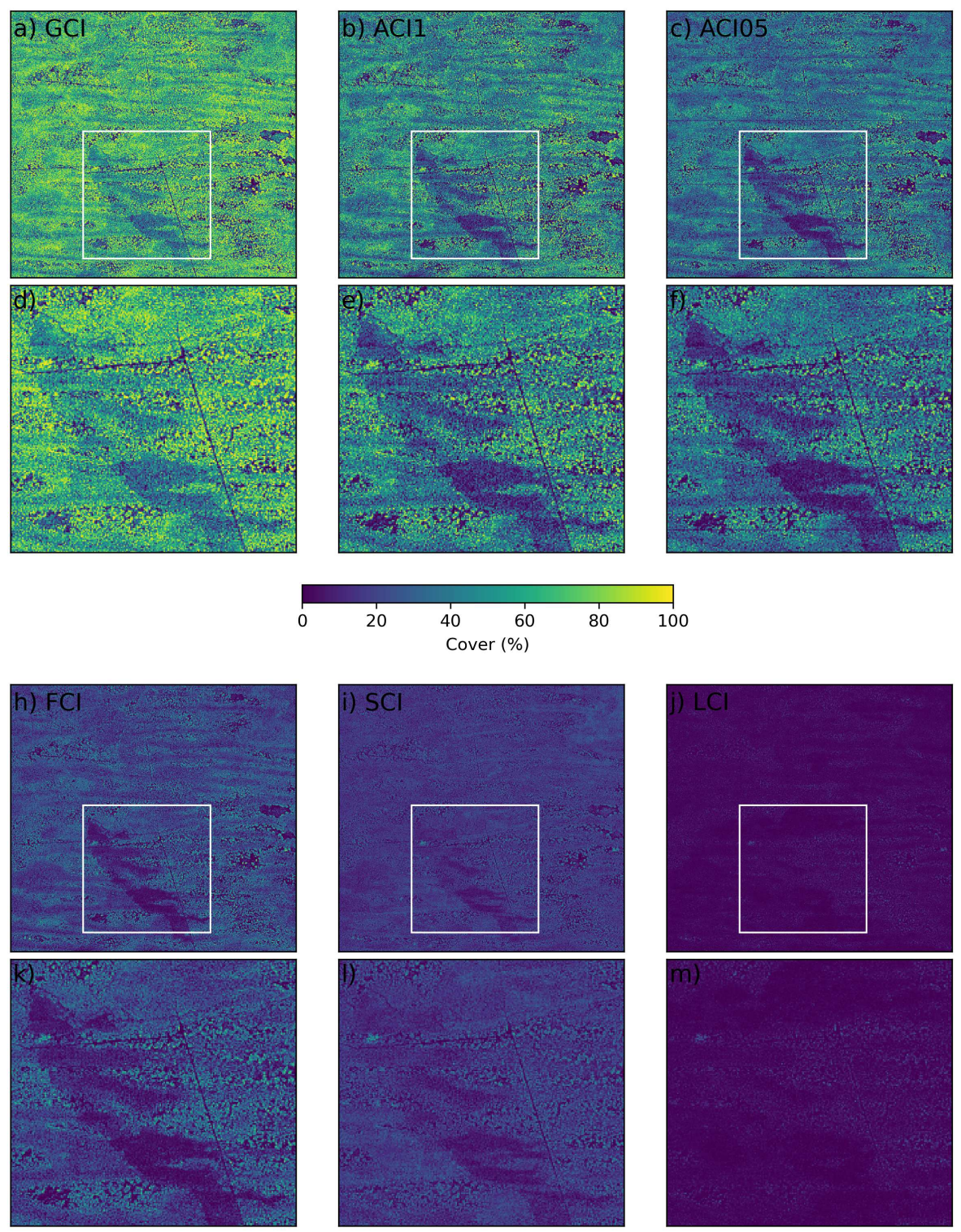

Fig. 4: Canopy cover maps produced from ALS data at $10 \mathrm{~m}$ grid resolution over $5 \mathrm{~km} \times 5 \mathrm{~km}$ study area. Parts (d, e, f, $\mathrm{k}, \mathrm{l}$ and $\mathrm{m}$ ) show the zoomed-in portion (white rectangle) of (a) GCI, (b) ACI1, (c) ACI05, (h) FCI, (i) SCI and (j) LCI cover estimates obtained from different algorithms. 


\subsection{Effect of canopy cover methods on fire simulations}

The predicted fires from the model were affected by the methods used to calculate canopy cover estimates. Simulations running with return-based cover estimates show slow progression of fire as compared to the simulations running with geometric-based cover estimates. In general, simulations running with single canopy cover method and for all ignition points reported similar predictions irrespective of the wind direction and ignition point combination as shown in Figure 1. This was observed for each of the canopy cover estimate method, and ignition point and wind direction combinations.

Figure 5 shows the progression of the fire over time for the canopy cover grids calculated using different methods at ignition point 1 . Results (total area burned and unburned area ratio within the fire perimeter) from this ignition point follows the similar trend to all other ignition points figures provided in Appendix A. The patterns of burned area indicated in Figure 5 are similar across all methods except LCI. A similar pattern for ratio of unburned area to total area in fire perimeter was observed. Notably each method showed the roads within the study area (seen as a linear feature at approximately half way through the burn) acting to slow the fire and resulting in areas being unburned. In return-based methods, the road appears to have a greater effect on the FCI method, despite a similar burned area estimate to that of SCI for all ignition points (\#1 and ignition points in Appendix A).

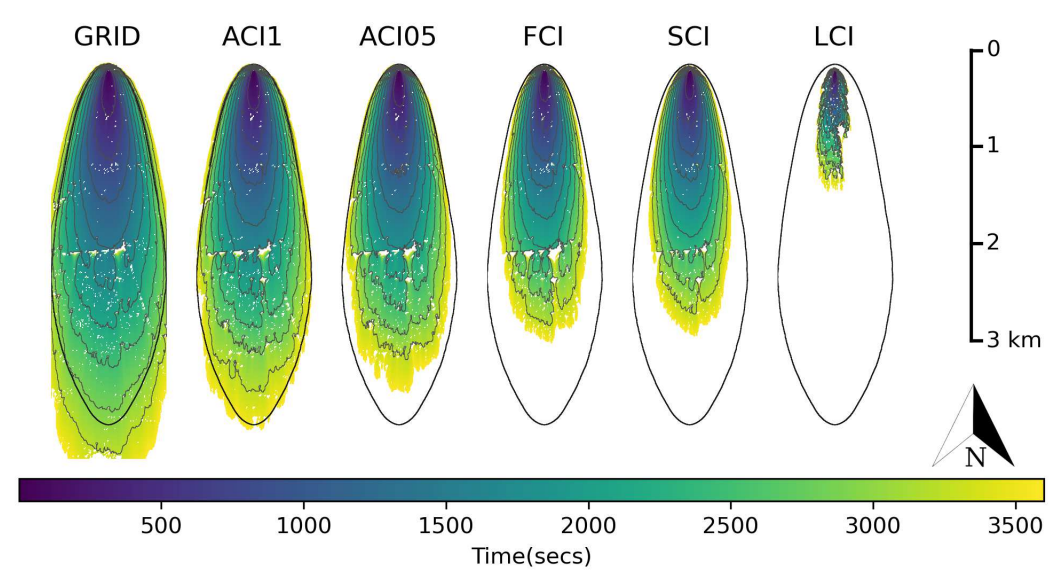

Fig. 5: Isochrones and arrival time plot for simulations from fire spread model at ignition point 1 using different cover methods over a duration of one hour. Black curve in each plot shows the fire simulated for a constant landscape. Whole area within black ellipse was burned. Grey contours shown in each plot represent the isochrones at six minute intervals $(10$ increments in total for each plot). North arrow shows the actual north direction. 
Figure 5 shows the progression of a sustained surface fire for simulations running with geometric-based cover estimates and the return-based methods FCI and SCI. This is evident in probability maps shown in Figure 6. These maps were generated using Equation (4) and show the probability of surface fire for each cover method. Figure 6 shows that more than $80 \%$ of the area is predicted to carry (probability $>50 \%$ ) a surface fire in simulations running using geometric-based cover estimates and the return-based methods FCI and SCI. Such conditions could result in a transition of surface fire to crown fires in this fuel type [2].

Simulations running with return-based cover estimates also show progression of sustained surface fire in some areas except the one running with LCI cover estimates Figure 5. Model simulations running with LCI cover estimates result in slowing down or extinguishing of the fire spread. Failure to spread surface fire using LCI cover estimates is evident in probability maps ( Figure 6j) where only $8 \%$ of the area is predicted for surface fire.

From Table 2 , it can be seen that $J(=0.84)$ is highest for simulations running with ACI1 metric, indicating that fires simulated with ACI1 metric become increasingly similar to the fire simulated for homogeneous landscape. Fire simulations with the GCI approach results in a greater burn area and a lower $J$ (Table 2). Whilst all return-based methods result in a lower burn area also resulting in a lower value of $J$. In general, once the fire had reached the same extent across the methods the shape of the burned area was similar, meaning that the interpretation of the Jaccard Index mostly relates to area burned in the simulated time.

Table 2: Summary results showing Mean $(\mu)$ and standard deviation $(\sigma)$ of burned area, unburned area ratio and Jaccard similarity index $(J)$ for different cover methods aggregated for all ignition points

\begin{tabular}{|c|c|c|c|c|c|c|}
\hline Canopy cover & \multicolumn{2}{|c|}{ burned area (ha) } & \multicolumn{2}{c|}{ Unburned area ratio (\%) } & \multicolumn{2}{c|}{ Jaccard Index $(J)$} \\
\hline methods & $\mu$ & $\sigma$ & $\mu$ & $\sigma$ & $\mu$ & $\sigma$ \\
\hline GRID & 419.60 & 50.71 & 3.12 & 0.5 & 0.70 & 0.026 \\
ACI1 & 340.66 & 33.15 & 3.91 & 0.60 & 0.84 & 0.060 \\
ACI05 & 294.16 & 25.70 & 4.05 & 0.69 & 0.83 & 0.056 \\
FCI & 215.70 & 13.62 & 4.06 & 1.1 & 0.55 & 0.05 \\
SCI & 184.71 & 16.27 & 2.84 & 0.63 & 0.65 & 0.045 \\
LCI & 29.89 & 5.78 & 13.31 & 1.83 & 0.09 & 0.018 \\
\hline
\end{tabular}



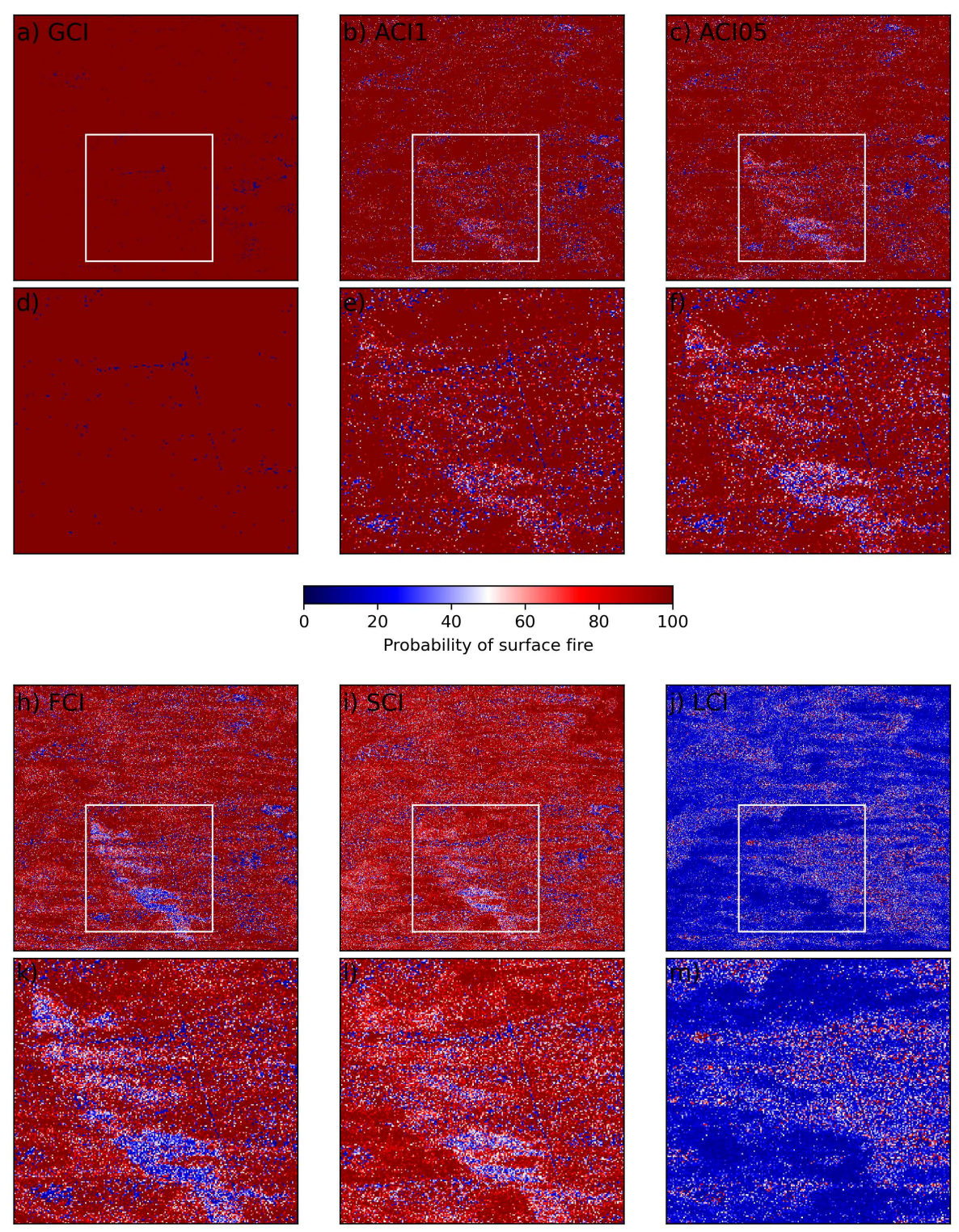

Fig. 6: Maps showing probability of surface fire over $5 \mathrm{~km} \times 5 \mathrm{~km}$ study area. Zoomed-in portion (white rectangle) in parts (d, e, f, k, l and m) show probability of surface fire predicted from Mallee-heath fire spread model by using cover estimates obtained from (a) GCI, (b) ACI1, (c) ACI05, (h) FCI, (i) SCI and (j) LCI methods. Blue represent 'self extinguishing/no-go', white represent transition from self-extinguishing to sustained fire spread and red represent sustained fire spread conditions. 


\subsection{Modelled burned area}

Figure 7 shows the total area burned by fire over a period of 60 minutes for each canopy cover grid obtained from different methods (also reported in Table 2) aggregated for all 10 ignition points, where the shading shows the $95 \%$ confidence interval. It is clear that the total area burned by fire is strongly affected by the method used to calculate canopy cover estimates. Simulations running with return-based cover estimates show less area covered by progression of fire as compared to the simulations run with geometricbased cover estimates. The cover estimates based on grid-based method show maximum mean area (419.60 ha) burned by fire and cover estimates based on LCI method show minimum mean area (29.89 ha) burned by fire. The confidence band is narrow for return-based cover estimates as compared to geometric-based cover estimates, although width of the band, representing the variation in the burned area, increases with time for all cover calculation algorithms. The area burned by fire simulated with ACI1 cover estimates is close to the area burned by a fire for homogeneous landscape (Figure 7).

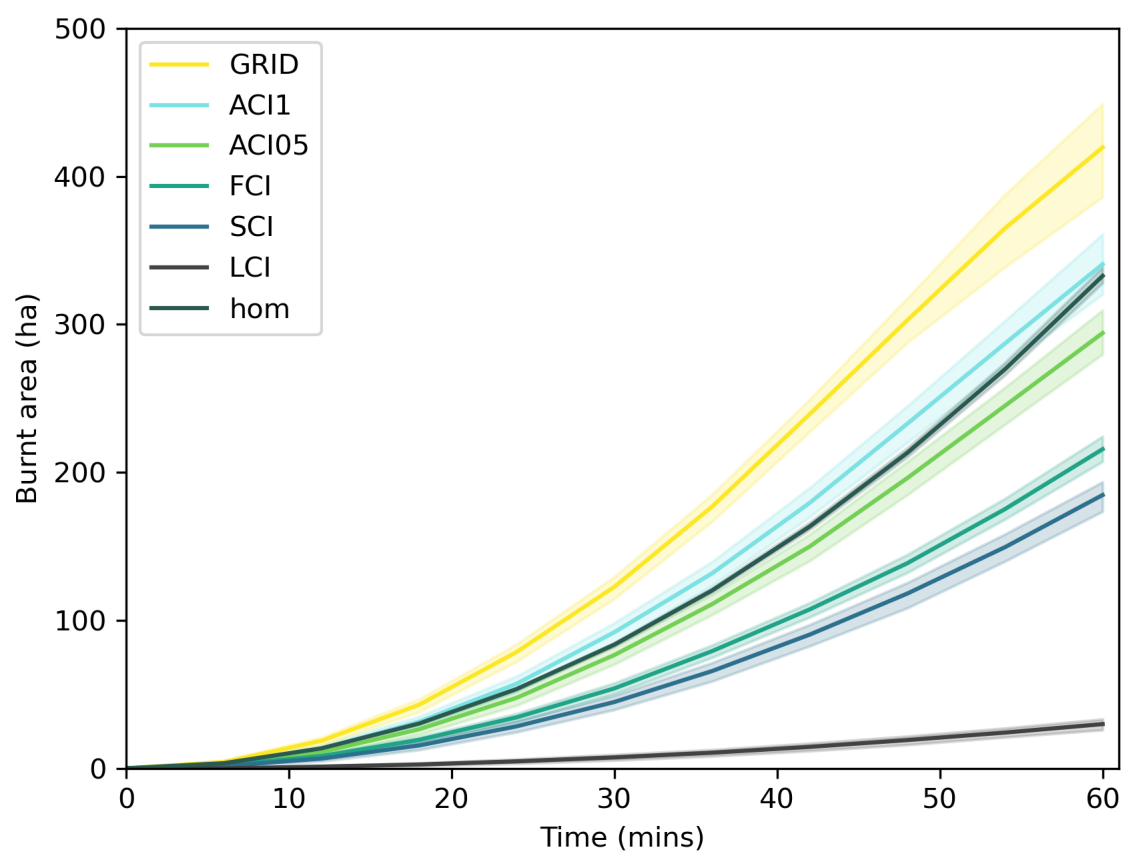

Fig. 7: Area burned by fire simulated with canopy cover percentage grids obtained from different canopy cover methods over an hour. 'hom' shows area burned by fire for homogeneous landscape. Shaded area shows $95 \%$ confidence interval for total burned area 


\subsection{Unburned area ratio}

Figure 8 illustrates the ratio of unburned area to total area in fire perimeter for all cover calculation algorithms (also reported in Table 2), aggregated for all of the ignition points. Simulations running with LCI method show maximum mean unburned area ratio and it could be attributed to the fact that roads were not encountered due to the low modelled fire extent. This ratio shows minimum variation in simulations running with grid-based methods. These minimum variations could be linked to the fact that irrespective of wind direction, simulations running with GCI method show maximum burned area for all ignition points.

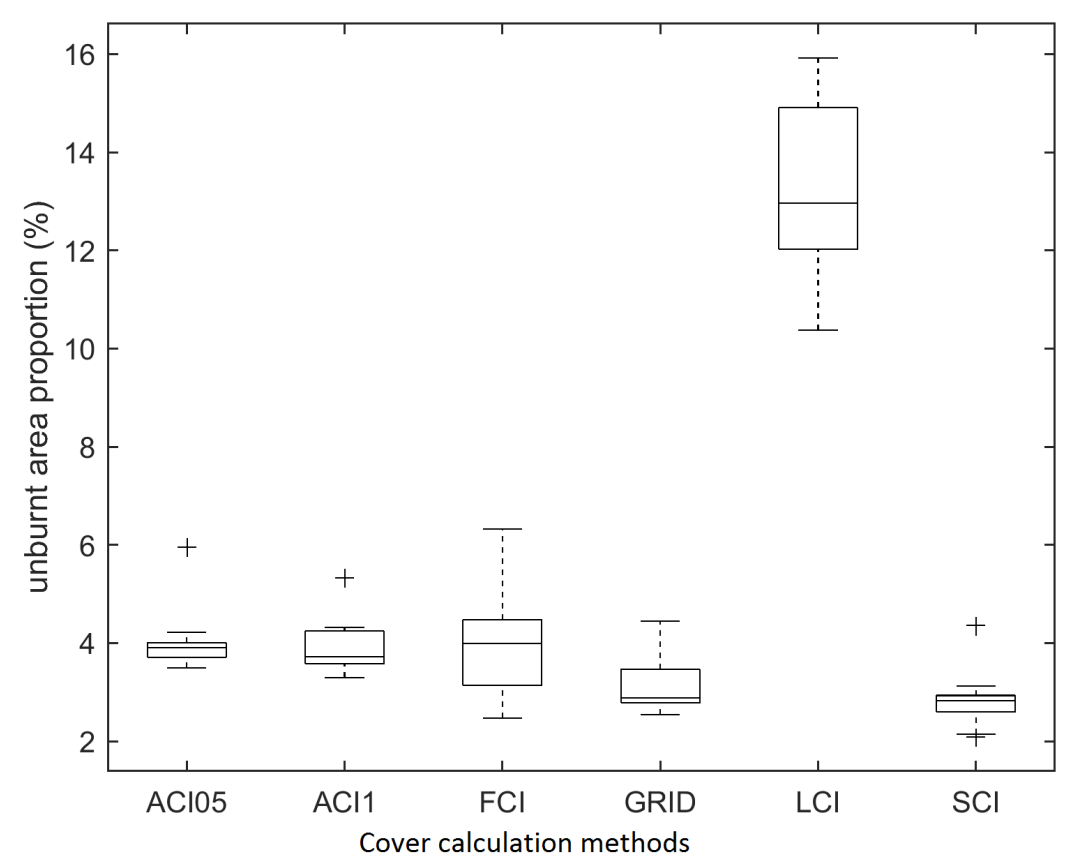

Fig. 8: Boxplot showing the ratio between the unburned area within the fire perimeter and the total area within the fire perimeter for all cover methods methods.

\section{Discussion}

In this study, we used five different published methods for deriving canopy cover estimates from ALS data. Our results indicate that different methods produce different canopy cover estimates in the Mallee-heath environment and in turn affect the outcomes of fire simulations. Primarily, estimates of canopy cover from return-based algorithms were found to be lower than the 
estimates from geometric-based algorithms. These results are consistent with results found in literature in other forest types [21, 31].

The geometric-based methods produce canopy cover estimates based on the $3 \mathrm{D}$ vegetation geometry represented within the point cloud and take into account all returns above $1.35 \mathrm{~m}$ rather than the complex interactions between the laser and the canopy. These methods do, however, make use of parameters which can result in different canopy cover estimates. These parameters are selected to account for variations in the pulse density of the ALS data. For example, a lower value of $\alpha$ in the ACI method will result in more canopy gaps and therefore a lower estimate of canopy cover. This will be exacerbated when the pulse density of the ALS data is lower than the chosen value of $\alpha$. In this case using an alpha value of 1 provided the similar estimates of cover to an infield digital canopy photography approach. Similarly, the GCI method relies on the resolution of the initial grid (in this case $1 \mathrm{x} 1 \mathrm{~m}$ ) and the size and shape of the kernel used in the opening and closing process. In this case, gaps which could be true canopy gaps or a result of low pulse density, are often neglected if they approach the grid size.

Of all the return-based canopy cover methods, the LCI method produces the lowest canopy cover estimates. As for all canopy cover metrics derived from ALS, it is a function of the complex interactions between canopy properties (i.e. canopy vegetation density, canopy length) and how returns are triggered in the scanner (i.e. the time between returns and amount of energy required to trigger a return). Within the Mallee-heath, trees are multi-stemmed and sparsely distributed across the landscape. The multi-stemmed structure of the trees contribute towards a number of last returns, with other last returns coming from the hummock and tussock grasses present in this understorey layer, or the ground ( Figure 2). In such environments, most of the LiDAR pulses are expected to be able to penetrate through the canopy and reach the understorey components and/or the ground directly without interacting in intermediate or upper canopy components which contribute almost negligible last returns in canopy as shown in Figure 2 within this study explaining the low canopy cover estimates produced using LCI.

In landscapes such as the Mallee-heath, that consist largely of discontinuous fuels in surface and canopy layers, with an absence of elevated and mid-storey fuel layers, the method used to compute canopy cover can result in significantly different fire behaviours observed, and this is shown in results of this study. For example: simulations running with LCI based cover estimates show slow progression or extinguishing behaviour of fire. This is due to minimum canopy cover estimates obtained using the LCI method. In simulations running with LCI derived cover layers, local features of landscape where fuels are organized in discrete clumps separated by bare ground acted as fire breaks, effectively stopping the fire, and resulting in small burned area and large unburned area ratio as reported in Table 2. Simulations running with LCI cover estimates do not reach the road irrespective of location of ignition points shown in figures in Section A. However, simulations running with geometric-based methods show 
progression of sustained surface fire ( Figure 6) with maximum area burned due to large estimation of canopy cover as shown in Figure 7. GCI cover estimates neglect canopy gaps and provide connectivity between fuel elements used in the model allowing the fire to propagate. Surface fire spread can lead to crown fire propagation and resulting high rates of spread. For some ignition points the area covered by the fire becomes patchy due to the presence of roads and discontinuities in the canopy. These act as breaks in the canopy, resulting in unburned areas.

These results have two implications for simulating fires in a forest with heterogeneous fuels using empirical modelling: (1) there can be significant differences in representing the canopy fuel as a homogeneous layer for ecosystems that include gaps; and (2) The method used to derive fuel metrics for models also influences modelled fire behaviour. In this context there is clear indication that cover metrics derived from LCI method cause the fire to effectively stop. The sensitivity of fire behaviour models to the variation in canopy cover descriptions highlighted in this study suggests the need to choose an appropriate method to derive input fuel data for fire behaviour models. Substantial gains in modelling fire behaviour could be made by incorporating a suitable method to derive inputs for fire behaviour models. Such developments could increase the application and accuracy of data-driven wildfire models [61, 62].

In addition to canopy cover estimates, the Mallee-heath empirical fire model requires other inputs that could also be derived from ALS data, such as canopy height and terrain. Careful consideration of how these metrics are calculated may also be required. For example, methods to calculate canopy height may include the percentile height, Lorey's height, maximum height and mean height of points within an area. These will result in difference in height values both in absolute (across the modelled area) and relative (between nearby cells) that may also result in modelled differences in fire spread. Furthermore, the resolution at which inputs for fire models are calculated [41] and terrain properties that may effect fire behaviour and predicting models derived from geospatial data.

Canopy cover metrics based on different methods have been shown in this study to result in different results when modelling fire behaviour, and it is conceivable that different vegetation types may also produce different results depending on the canopy cover method used. Consistent documentation of methods is recommended to prepare correct inputs for fire simulation models. Doing this would enable fire behaviour phenomena to be documented and analysed, and ensures that results are reproducible. Ideally, the method used to derive the cover metrics in a particular environment should be tested with field measurements to ensure the accuracy of observations and their description of structure, before using them in a fire behavior model. The choice of method used should be guided by assessing the relative accuracy of derived data against reference data collected (using similar the infield approaches which were employed to measure the variable when developing the empirical model). For example, if a model was developed based on field measures of LAI 
or angular canopy cover, using vertical canopy cover derived from the ALS data as an input to fire model will not result in consistent results. As such it is important that the methods used to collect and describe fuel when developing a model are fully described and remotely sensed metrics are related to that physical attribute before using them as input into the model.

\section{Conclusions}

Empirical fire models are routinely used in fire management operations to predict fire spread and associated risks, and these models require fuel data. Whilst remote sensing approaches such as ALS offer opportunities to provide input into these models, there are currently a wide variety of methods used to derive estimates of fuel attributes from such data. This study assessed the impact of different methods to calculate canopy cover estimates on the performance of an empirical fire behaviour model in a Mallee-heath. Our results show that different algorithms to derive cover from ALS data produce different canopy cover estimates and, in turn, different fire behaviour predictions (including extent and pattern). Simulations running with geometric-based cover estimates resulted in higher estimates of burned area and maximum number of unburned patches as compared to simulations running with return-based cover estimates. Grid-based cover estimates neglect canopy gaps and provide connectivity between fuel elements used in the model allowing the fire to propagate. When the canopy cover estimate were lower (for example in using the returnbased approach) features such as gaps and patchy data in the fuel led to the predicted fire simulations being slowed or stopped. These results demonstrate that methods for determining fuel inputs into fire behaviour models should be chosen based on the properties of the data, the vegetation structure present in an area and how the input was determined in developing the model. Without this level of rigour, the use of remote sensing data as inputs into a fire behaviour model will likely not provide the expected results or performance from that model.

Acknowledgments. The support provided by RMIT University School of Science scholarship stipend program and the CSIRO Data61 top-up scholarship program are gratefully acknowledged. Data was sourced from Terrestrial Ecosystem Research Network (TERN) infrastructure, which is enabled by the Australian Government's National Collaborative Research Infrastructure Strategy (NCRIS).

Funding. The authors declare that no funds, grants, or other support were received for this research.

data availability. ALS data for this study is available on https://cloudstor.aarnet.edu.au/plus/s/B3CXHxIvs2hfdOI

conflicts of interest. The authors declare no conflict of interest. 
Author Contributions. All authors contributed to the study conception and design. Material preparation, Methodology and analysis were performed by RT, LW and JH. Validation was performed by RT and LW. Supervision for this study was performed by LW, JH, KR and SJ. The first draft of the manuscript was written by RT and all authors commented on previous versions of the manuscript. All authors read and approved the final manuscript."

Code availability. Not applicable

\section{Appendix A}

Isochrone and arrival time plots showing simulated fire spread computed from the different cover methods for 10 different ignition points for the duration of one hour. The black polygon in each plot represents the simulated area burned for a landscape with constant canopy cover. Grey linework shown in each plot represents the isochrones at six minute intervals.

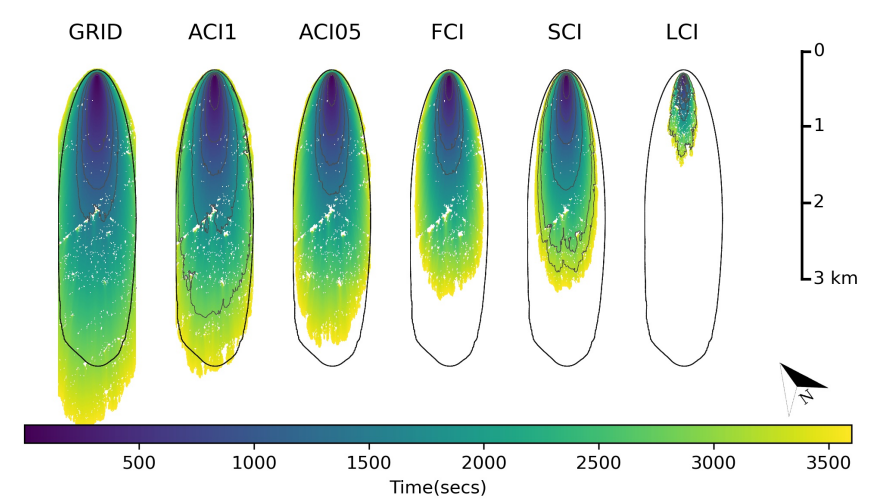

Fig. A1: Isochrones and arrival time plot for simulations from fire spread model at ignition point 2 using different cover methods over a duration of one hour. Black curve in each plot shows the fire simulated for a constant landscape. Whole area within black ellipse was burned. Grey contours shown in each plot represent the isochrones at six minute intervals (10 increments in total for each plot). North arrow shows the actual north direction. 


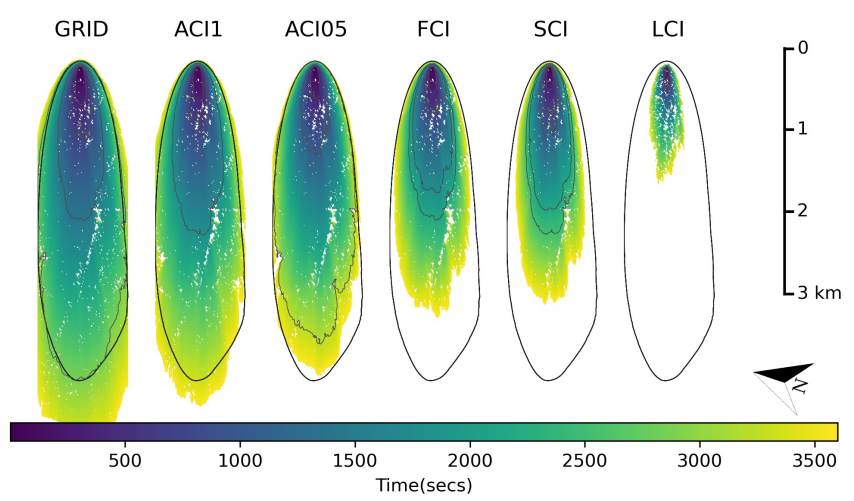

Fig. A2: Isochrones and arrival time plot for simulations from fire spread model at ignition point 3 using different cover methods over a duration of one hour. Black curve in each plot shows the fire simulated for a constant landscape. Whole area within black ellipse was burned. Grey contours shown in each plot represent the isochrones at six minute intervals (10 increments in total for each plot). North arrow shows the actual north direction.

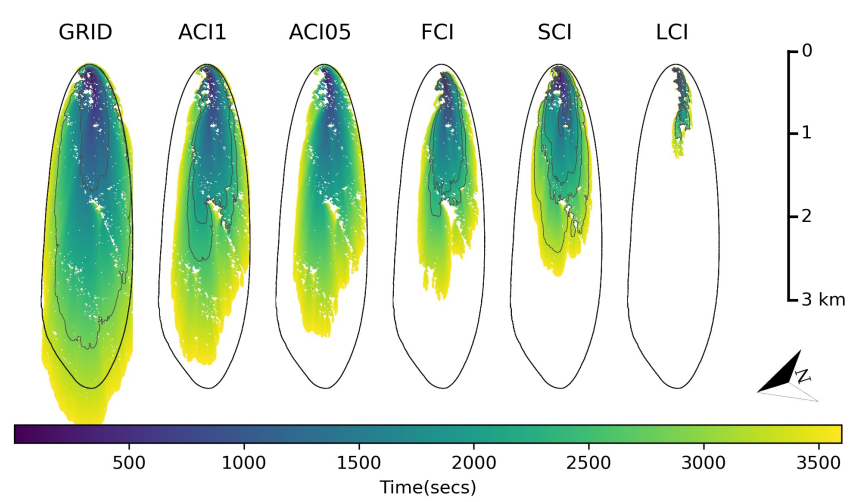

Fig. A3: Isochrones and arrival time plot for simulations from fire spread model at ignition point 4 using different cover methods over a duration of one hour. Black curve in each plot shows the fire simulated for a constant landscape. Whole area within black ellipse was burned. Grey contours shown in each plot represent the isochrones at six minute intervals (10 increments in total for each plot). North arrow shows the actual north direction. 


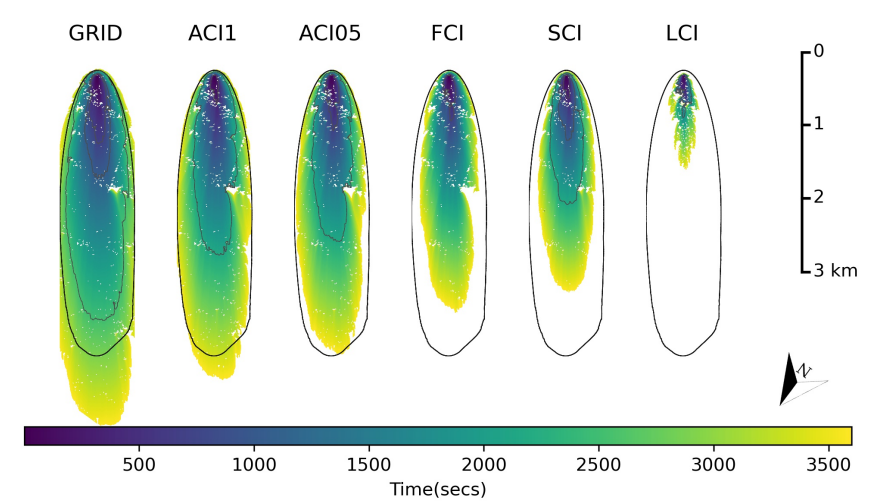

Fig. A4: Isochrones and arrival time plot for simulations from fire spread model at ignition point 5 using different cover methods over a duration of one hour. Black curve in each plot shows the fire simulated for a constant landscape. Whole area within black ellipse was burned. Grey contours shown in each plot represent the isochrones at six minute intervals (10 increments in total for each plot). North arrow shows the actual north direction.

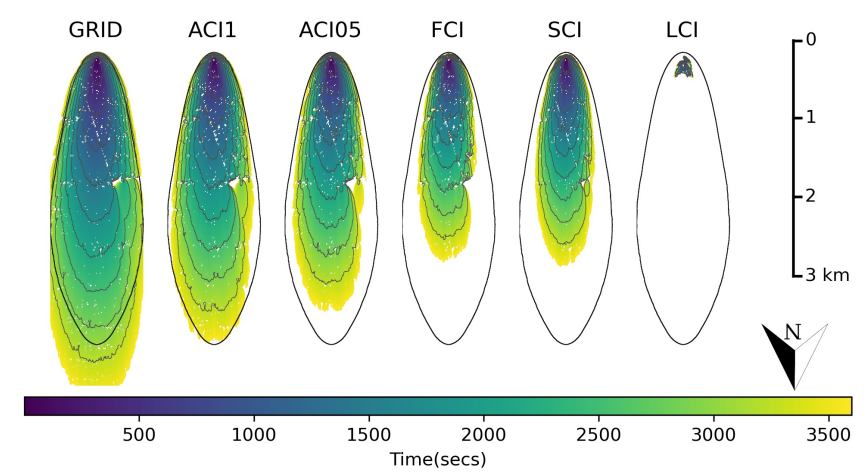

Fig. A5: Isochrones and arrival time plot for simulations from fire spread model at ignition point 6 using different cover methods over a duration of one hour. Black curve in each plot shows the fire simulated for a constant landscape. Whole area within black ellipse was burned. Grey contours shown in each plot represent the isochrones at six minute intervals (10 increments in total for each plot). North arrow shows the actual north direction. 


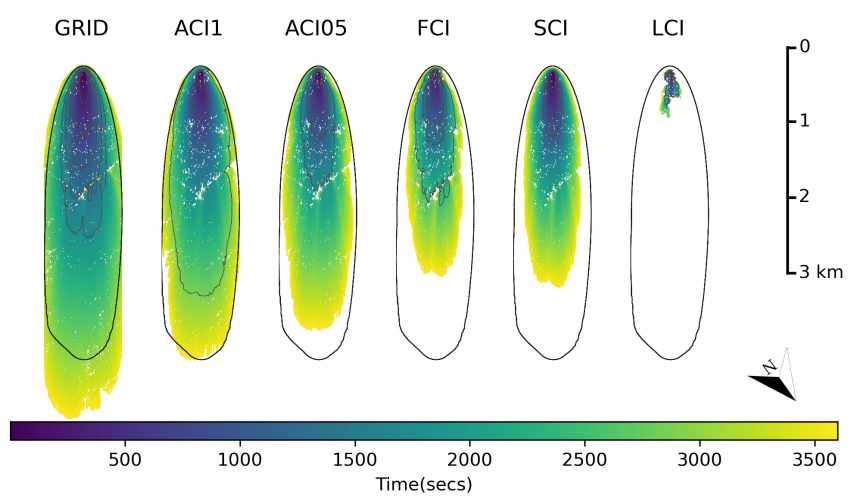

Fig. A6: Isochrones and arrival time plot for simulations from fire spread model at ignition point 7 using different cover methods over a duration of one hour. Black curve in each plot shows the fire simulated for a constant landscape. Whole area within black ellipse was burned. Grey contours shown in each plot represent the isochrones at six minute intervals (10 increments in total for each plot). North arrow shows the actual north direction.

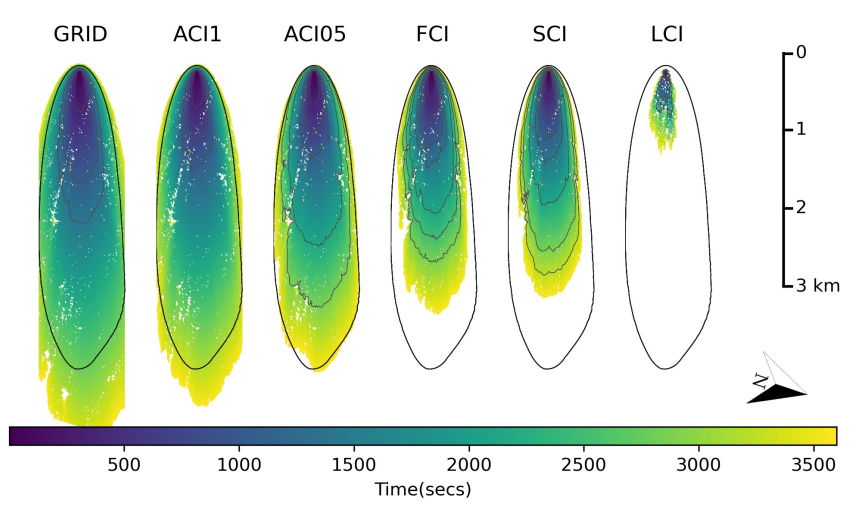

Fig. A7: Isochrones and arrival time plot for simulations from fire spread model at ignition point 8 using different cover methods over a duration of one hour. Black curve in each plot shows the fire simulated for a constant landscape. Whole area within black ellipse was burned. Grey contours shown in each plot represent the isochrones at six minute intervals (10 increments in total for each plot). North arrow shows the actual north direction. 


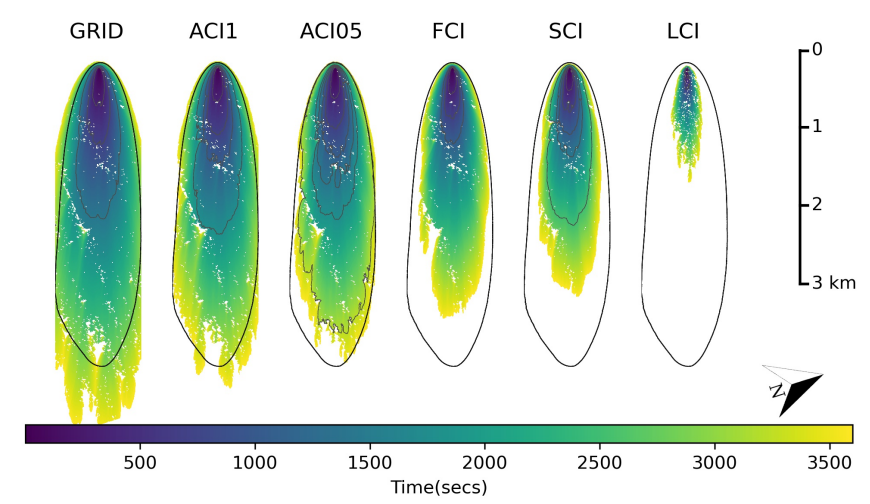

Fig. A8: Isochrones and arrival time plot for simulations from fire spread model at ignition point 9 using different cover methods over a duration of one hour. Black curve in each plot shows the fire simulated for a constant landscape. Whole area within black ellipse was burned. Grey contours shown in each plot represent the isochrones at six minute intervals (10 increments in total for each plot). North arrow shows the actual north direction.

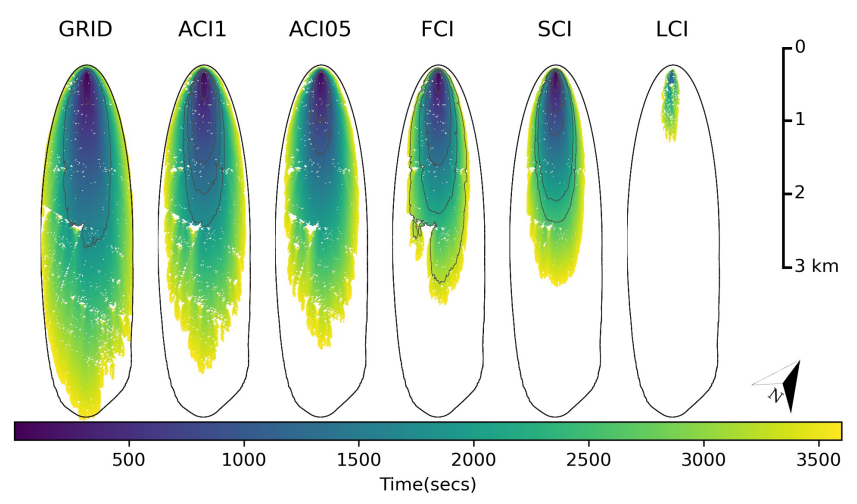

Fig. A9: Isochrones and arrival time plot for simulations from fire spread model at ignition point 10 using different cover methods over a duration of one hour. Black curve in each plot shows the fire simulated for a constant landscape. Whole area within black ellipse was burned. Grey contours shown in each plot represent the isochrones at six minute intervals (10 increments in total for each plot). North arrow shows the actual north direction.

\section{References}

[1] Enright, N., Keith, D., Clarke, M., Miller, B.: Fire Regimes in Australian 
Sclerophyllous Shrubby Ecosystems: Heathlands, Heathy Woodlands and Mallee Woodlands, pp. 215-234. CSIRO Publishing, Australia (2012)

[2] Cruz, M.G., McCaw, W.L., Anderson, W.R., Gould, J.S.: Fire behaviour modelling in semi-arid mallee-heath shrublands of southern australia. Environmental Modelling and Software 40, 21-34 (2013)

[3] Pausas, J., Llovet, J., Rodrigo, A., Vallejo, R.: Are wildfires a disaster in the mediterranean basin? - a review. International Journal of Wildland Fire 17, 713-723 (2008). https://doi.org/10.1071/WF07151

[4] Gould, J., McCaw, W., Cheney, N., Ellis, P., Knight, I., Sullivan, A.: Project Vesta - Fire in Dry Eucalypt Forest: Fuel Structure, Fuel Dynamics and Fire Behavior. CSIRO Publishing, Bushfire CRC (2007)

[5] Atchley, A.L., Linn, R., Jonko, A., Hoffman, C., Hyman, J.D., Pimont, F., Sieg, C., Middleton, R.S.: Effects of fuel spatial distribution on wildland fire behaviour. International Journal of Wildland Fire 30(3), 179-189 (2021)

[6] Bradstock, R., Gill, M., Richards, W.: chapter 10. FLAMMABLE AUSTRALIA. CSIRO Publications, Dordrecht (2012). https://doi.org/10. $1071 / 9780643104839$

[7] Lippitt, C.L., Stow, D.A., O’Leary, J.F., Franklin, J.: Influence of shortinterval fire occurrence on post-fire recovery of fire-prone shrublands in california, usa. International Journal of Wildland Fire 22, 184-193 (2013). http://dx.doi.org/10.1071/WF10099

[8] McCaw, W.: Predicting fire spread in western australian mallee-heath shrubland. IEEE Journal of Selected Topics in Applied Earth Observations and Remote Sensing PhD Thesis (1997)

[9] Burrows, N., Ward, B., Robinson, A.: Fuel dynamics and fire spread in spinifex grasslands of the western desert. Proceedings of the Royal Society of Queensland, 69-76 (2009)

[10] Pimont, F., Dupuy, J.-L., Linn, R.: Impacts of tree canopy structure on wind flows and fire propagation simulated with firetec. Annals of Forest Science 68, 523-530 (2011)

[11] Linn, R., Sieg, C., Hoffman, C., Winterkamp, J., McMillin, J.: Modeling wind fields and fire propagation following bark beetle outbreaks in spatially heterogeneous pinyon-juniper woodland fuel complexes. Agricultural and Forest Meteorology 173, 139-153 (2013)

[12] Hilton, J.E., Miller, C., Sullivan, A.L., Rucinski, C.: Effects of spatial and 
temporal variation in environmental conditions on simulation of wildfire spread. Environmental Modelling \& Software 67, 118-127 (2015)

[13] Hoffman, C., Linn, R., Parsons, R., Sieg, C., Winterkamp, J.: Modeling spatial and temporal dynamics of wind flow and potential fire behavior following a mountain pine beetle outbreak in a lodgepole pine forest. Agricultural and Forest Meteorology 204, 79-93 (2015)

[14] Parsons, R., Linn, R., Pimont, F., Hoffman, C., Sauer, J., Winterkamp, J., Sieg, C., W, J.: Numerical investigation of aggregated fuel spatial pattern impacts on fire behavior. Land $6 \mathbf{4 3}$ (2017)

[15] Ziegler, J., Hoffman, C., Battaglia, M., Mell, W.: An easy-to-use airborne lidar data filtering method based on cloth simulation. Forest Ecology and Management 386, 1-12 (2017)

[16] Pause, M., Schweitzer, C., Rosenthal, M., Keuck, V., Bumberger, J., Dietrich, P., Heurich, M., Jung, A., Lausch, A.: In situ/remote sensing integration to assess forest health - a review. Remote Sensing 8(6), 471 (2016)

[17] Lausch, A., Erasmi, S., King, D.J., Magdon, P., Heurich, M.: Understanding forest health with remote sensing-part ii - a review of approaches and data models. Remote Sensing 9(2), 129 (2017)

[18] Matese, A., Toscano, P., Di Gennaro, S.F., Genesio, L., Vaccari, F.P., Primicerio, J., Belli, C., Zaldei, A., Bianconi, R., Gioli, B.: Intercomparison of uav, aircraft and satellite remote sensing platforms for precision viticulture. Remote Sensing 7(3), 2971-2990 (2015)

[19] Dubayah, R.: The gedi strategy for improved mapping of forest biomass and structure. The GEDI Science Team (2017) AGU Fall Meeting, New Orleans, LA, USA. B11H-06 (2017)

[20] Dubayah, R., Blair, J., Goetz, S., Fatoyinbo, L., Hansen, M., Healey, S., Hofton, M., Hurtt, G., Kellner, J., Luthcke, S., Armston, J.: The global ecosystem dynamics investigation: High-resolution laser ranging of the earth's forests and topography. Science of Remote Sensing 1(100002), 973-981 (2017). https://doi:10.1016/J.SRS.2020.100002

[21] Korhonen, L., Korpela, I., Heiskanen, J., Maltamo, M.: Airborne discretereturn lidar data in the estimation of vertical canopy cover, angular canopy closure and leaf area index. Remote Sensing of Environment 115(4), 1065-1080 (2011)

[22] Lefsky, M., Cohen, W., Parker, G., Harding, D.: Lidar remote sensing for ecosystem studies. Bioscience 52, 19-30 (2002). doi:10.1641/ 
0006-3568(2002)052[0019:LRSFES]2.0.CO;2

[23] Alexander, M., Cruz, M.: Using lidar technology in forestry activities. Environmental Monitoring and Assessment 15(1), 117-125 (2009). https: //doi:10.1007/s10661-008-0254-1

[24] Erdody, T., Moskal, L.: Fusion of lidar and imagery for estimating forest canopy fuels. Remote Sensing of Environment 114, 725-737 (2010)

[25] Lim, K., Treitza, P., Wulder, M., St-Onge, B., Flood, M.: Lidar remote sensing of forest structure. Progress in Physical Geography 27(1), 88-106 (2003). http://doi:10.1191/0309133303PP360RA

[26] Hopkinson, C., Chasmer, L.: Testing lidar models of fractional cover across multiple forest ecozones. Remote Sensing of Environment 113, 275-288 (2009)

[27] Hancock, S., Anderson, K., Disney, M., Gaston, K.: Measurement of finespatial-resolution $3 \mathrm{~d}$ vegetation structure with airborne waveform lidar: Calibration and validation with voxelised terrestrial lidar. Remote Sensing of Environment 188, 37-50 (2017)

[28] Wulder, M.A., White, J.C., Nelson, R.F., Næsset, E., Ørka, H.O., Coops, N.C., Hilker, T., Bater, C.W., Gobakken, T.: Lidar sampling for largearea forest characterization: A review. Remote Sensing of Environment 121, 196-209 (2012)

[29] Korhonen, L., Heiskanen, J., Korpela, I.: Modelling lidar-derived boreal forest canopy cover with spot 4 hrvir data. International Journal of Remote Sensing 34(22), 8172-8181 (2013)

[30] Korhonen, L., Morsdorf, F.: Estimation of Canopy Cover, Gap Fraction and Leaf Area Index with Airborne Laser Scanning vol. 1, pp. 397-417. Springer, Netherlands (2014)

[31] Wallace, L.: Assessing the stability of canopy maps produced from uav-lidar data. IEEE International Geoscience and Remote Sensing Symposium IGARSS, 3879-3882 (2013). https://doi.10.1109/IGARSS.2013. 6723679

[32] Ma, Q., Su, Y., Guo, Q.: Comparison of canopy cover estimations from airborne lidar, aerial imagery, and satellite imagery. IEEE Journal of Selected Topics in Applied Earth Observations and Remote Sensing 10(9), 4225-4236 (2017)

[33] Holmgren, J., Nilsson, M., Olsson, H.: Simulating the effects of lidar scanning angle for estimation of mean tree height and canopy closure. 
Canadian Journal of Remote Sensing 29(5), 623-632 (2003)

[34] Hopkinson, C.: The influence of flying altitude, beam divergence, and pulse repetition frequency on laser pulse return intensity and canopy frequency distribution. Canadian Journal of Remote Sensing 33(4), 312-324 (2007)

[35] TERN: Airborne LiDAR - raw and QA data for all sites. http://www. tern.org.au (2012)

[36] Meyer, W., Kondrlovà, E., Koerber, G.: Evaporation of perennial semiarid woodland in southeastern australia is adapted for irregular but common dry periods. Hydrological Processes 29(17), 3714-3726 (2015)

[37] Department for Environment and Heritage: Bookmark mallee fire management plan. Technical report, Department for Environment and Heritage (sep 2009)

[38] O'Donnell, A., Boer, M., McCaw, W., Grierson, P.: Vegetation and landscape connectivity control wildfire intervals in unmanaged semi-arid shrublands and woodlands in australia. Journal of Biogeography $\mathbf{3 8 7}$

[39] Reigel: Airborne Data-Processing Software or Full Waveform Analysis RiANALYZE 560.270 Horn, Austria (2006)

[40] Zhang, W., Qi, J., Wan, P., Wang, H., Xie, D., Wang, X., Yan, G.: An easy-to-use airborne lidar data filtering method based on cloth simulation. Remote Sensing 8(6), 501 (2016)

[41] Taneja, R., Hilton, J., Wallace, L., Reinke, K., Jones, S.: Effect of fuel spatial resolution on predictive wildfire models. International Journal of Wildland Fire (2021). https://doi.org/10.1071/WF20192

[42] Mahoney, C., Hopkinson, C., Held, A., Kljun, N., Van Gorsel, E.: Ice-sat/glas canopy height sensitivity inferred from airborne lidar. Photogrammetric Engineering and Remote Sensing 82(5), 351-363 (2016). https://dOI:10.14358/PERS.82.5.351

[43] Mahoney, C., Hopkinson, C., Held, A., Simard, M.: Continental-scale canopy height modeling by integrating national, spaceborne, and airborne lidar data. Canadian Journal of Remote Sensing 42(5), 574-590 (2016). https://doi.org/10.1080/07038992.2016.1196580

[44] McLane, A.J., McDermid, G.J., Wulder, M.A.: Processing discrete-return profiling lidar data to estimate canopy closure for large-area forest mapping and management. Canadian Journal of Remote Sensing 35(3), 217-229 (2009) 
[45] Morsdorf, F., Kötz, B., Meier, E., Itten, K., Allgöwer, B.: Estimation of lai and fractional cover from small footprint airborne laser scanning data based on gap fraction. Remote Sensing of Environment 104(1), 50-61 (2006)

[46] Solberg, S., Brunner, A., Hanssen, K.H., Lange, H., Næsset, E., Rautiainen, M., Stenberg, P.: Mapping lai in a norway spruce forest using airborne laser scanning. Remote Sensing of Environment 113(11), 23172327 (2009)

[47] Meyer, Wayne: Leaf Area Index Data, Calperum Mallee SuperSite, Core 1 ha, 2013. TERN Australian SuperSite Network. http://supersites.tern. org.au/knb/metacat/supersite.277.15/html

[48] Macfarlane, C., Hoffman, M., Eamus, D., Kerp, N., Higginson, S., McMurtrie, R., Adam, M.: Estimation of leaf area index in eucalypt forest using digital photography. Agricultural and Forest Meteorology 143(3-4), 176-188 (2007). https://doi.org/10.1016/j.agrformet.2006.10.013.

[49] Pekin, B., Macfarlane, C.: Measurement of crown cover and leaf area index using digital cover photography and its application to remote sensing. Remote Sensing 1(4), 1298-1320 (2009). https://doi.org/10.3390/ rs1041298

[50] Miller, C., Hilton, J., Sullivan, A., Prakash, M.: Spark-a bushfire spread prediction tool. In: International Symposium on Environmental Software Systems, pp. 262-271 (2015). Springer

[51] Hilton, J., Swedosh, W., Hetherton, L., Sullivan, A., Prakash, M.: Spark user guide 1.1.2. Technical report, CSIRO (2019)

[52] Cruz, M.G., Alexander, M.E., Sullivan, A.L.: Mantras of wildland fire behaviour modelling: facts or fallacies? International Journal of Wildland Fire 26(11), 973-981 (2017). https://doi.org/10.1071/WF17097

[53] Luo, Y., Weng, E.: Dynamic disequilibrium of the terrestrial carbon cycle under global change. Trends in Ecology and Evolution 26(2), 96-104 (2011)

[54] Johnston, F.H., Henderson, S.B., Chen, Y., Randerson, J.T., Marlier, M., DeFries, R.S., Kinney, P., Bowman, D.M., Brauer, M.: Estimated global mortality attributable to smoke from landscape fires. Environmental health perspectives 120(5), 695-701 (2012)

[55] Kloster, S., Mahowald, N., Randerson, J., Lawrence, P.: The impacts of climate, land use, and demography on fires during the 21st century simulated by clm-cn. Biogeosciences 9(1), 509-525 (2012) 
[56] Kolden, C.A., Lutz, J.A., Key, C.H., Kane, J.T., van Wagtendonk, J.W.: Mapped versus actual burned area within wildfire perimeters: characterizing the unburned. Forest Ecology and Management 286, 38-47 (2012)

[57] Kolden, C.A., Abatzoglou, J.T., Lutz, J.A., Cansler, C.A., Kane, J.T., Van Wagtendonk, J.W., Key, C.H.: Climate contributors to forest mosaics: ecological persistence following wildfire. Northwest Science 89(3), 219-238 (2015)

[58] Krawchuk, M.A., Haire, S.L., Coop, J.D., Parisien, M.-A., Whitman, E., Chong, C. Geneva W.and Miller: Topographic and fire weather controls of fire refugia in forested ecosystems of northwestern north america. Ecosphere 7(12), 1-18 (2016). https://doi.org/10.1002/ecs2.1632

[59] Cruz, M.G., Gould, J.S., Alexander, M.E., Sullivan, A.L., McCaw, W.L., Matthews, S.: A Guide to Rate of Fire Spread Models for Australian Vegetation. Australasian Fire and Emergency Service Authorities Council Limited, Canberra (2015)

[60] Kalabokidis, K., Palaiologou, P., Finney, M.A.: Fire behavior simulation in mediterranean forests using the minimum travel time algorithm. In: In: Fourth Fire Behavior and Fuels Conference Proceedings-At The Crossroads: Looking Toward the Future in a Changing Environment; July 1-4, 2013; St. Petersburg, Russia. Missoula, MT: International Association of Wildland Fire, pp. 468-492 (2014)

[61] Coen, J., Cameron, M., Michalakes, J., Patton, E., Riggan, P., KM, Y.: Wrf-fire: coupled weather-wildland fire modeling with the weather research and forecasting model. Journal of Applied Meteorology and Climatology 52, 16-38 (2013). https://doi:10.1175/JAMC-D-12-023.1

[62] Coen, J., Schroeder, W.: Use of spatially refined satellite remote sensing fire detection data to initialize and evaluate coupled weather- wildfire growth model simulations. Geophysical Research Letters 40, 5536-5541 (2013). https://doi.org/10.1071/WF17097 